114

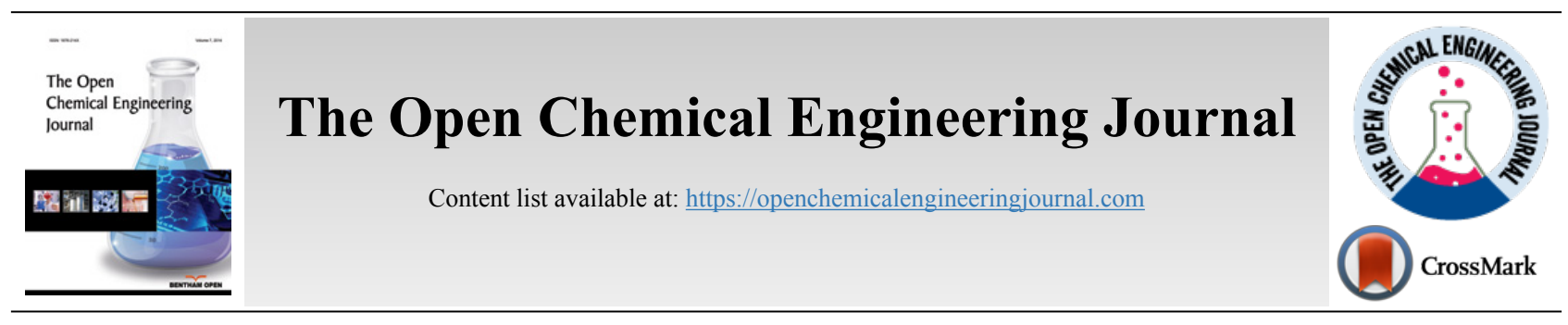

RESEARCH ARTICLE

\title{
Experimental Study on Rational Water Injection Rate in Continental Sandstone Reservoirs
}

\author{
Manping Yang ${ }^{1,+, *}$, Lu Jiang $^{1}$, Shuxiang Guo ${ }^{1}$, Liming Zheng ${ }^{1}$ and Ling Meng ${ }^{1}$ \\ ${ }^{1}$ Petroleum Engineering Department, Yanshan University, Hebei, China
}

\begin{abstract}
:
Objective:

In this paper, an experimental model of water flooding was designed and manufactured, and experiments on high permeability and low permeability models were carried out.

Methods:

The relationship between injection rate, injection pore volume multiple and oil displacement efficiency, injection rate, injection pore volume multiple and water content in two kinds of permeability was analyzed.

Results:

There is a certain relationship between oil displacement efficiency and water injection speed. There is a reasonable water injection speed, which can achieve the highest oil displacement efficiency. The lower the permeability the lower will be the reasonable injection rate . In the reasonable range of water injection rate, the injection rate increases gradually, and the best oil displacement effect can be obtained.

\section{Conclusion:}

Through analysis, it was concluded that the oil displacement efficiency of artificial rocks with various water injection rates was different even in the same permeability experimental model. It was indicated that the water flooding recovery of the reservoir can be improved by using the method of strong injection and strong production in the middle and later stage of development.
\end{abstract}

Keywords: Sandstone reservoir, Water drive, Injection rate, Injection pore volume multiple, Oil displacement efficiency, Permeability.

\begin{tabular}{|c|c|c|c|}
\hline Article History & Received: April 10, 2019 & Revised: July 15, 2019 & Accepted: August 31, 2019 \\
\hline
\end{tabular}

\section{INTRODUCTION}

Continental sandstone reservoirs were the most widely distributed reservoir types in China. They were characterized by complex structural characteristics, great differences in reservoir physical and fluid properties, and strong reservoir heterogeneity $[1,2]$. Water flooding development had the characteristics of short stable production period, rapid decline in production and rapid increase in water cut [1]. At present, most of the water flooding reservoirs had entered the middle and high water-cut development period, and some reservoirs had even entered the ultra-high water-cut development period, facing difficult production situation. Although water flooding had some limitations, it was still the most widely used and

* Address correspondence to this author at Petroleum Engineering Department, Yanshan University, Hebei, China; Tel: 15503350808;

E-mail: yangmp@ysu.edu.cn mature reservoir development method. Therefore, how to improve the efficiency of water flooding development in sandstone reservoirs had always been the focus of research [3-6].

Laboratory water flooding experiment was the most common method to study the water flooding law of reservoirs. Various displacement experiments were carried out on natural or artificial cores to study the mechanism of water flooding [7 $10]$, the change rules of water content and displacement efficiency $[11,12]$, the main factors affecting water flooding efficiency [13 - 16] and the relative permeability characteristics of oil and water phases [17 - 20]. The research results can provide guidance and basis for oilfield development and experimental basis for the study of oil-water two-phase flow.

This experiment was intended to establish an experimental model to study the water content and oil displacement 
efficiency of the same experimental model under different injection rates [21 - 24], and to find a reasonable injection rate to guide the development of water flooding reservoirs.

\section{EXPERIMENTAL SCHEME DESIGNS}

\subsection{Experimental Model Design}

The experimental model used a sand-filled tube whose inner wall was frosted to prevent turbulence. The inner diameter was $3.8 \mathrm{~mm}$ and the length was $30 \mathrm{~mm}$. Fine artificial sand was screened and filled in the sand-filled tube with cement. After standing for $48 \mathrm{~h}$. and the rock was fully cemented, the sand-filled tube was put into oven for drying.

In this experiment, two combinations of high permeability and low permeability were designed, which were filled under the same conditions to ensure that they could be used for experimental comparative analysis. Among them, there were 8 sand-filled tube models of high permeability, the porosity was $38.6 \%$ and gas permeability of $686.5 \times 10-3 \mu \mathrm{m} 2$.

There were 6 sand-filled tube models of low permeability,the porosity was $21.4 \%$ and the gas permeability was $42.8 \times 10-3 \mu \mathrm{m} 2$. The drying sand-filled tube first infused water, and then established an experimental model containing irreducible water through the oil flooding water. The experimental oil was made from simulated kerosene and degassed crude oil. The viscosity of crude oil was $4.7 \mathrm{mPa} \cdot \mathrm{S}$. The displacement fluid was distilled water with a viscosity of $1 \mathrm{mPs} \cdot \mathrm{s}$.

\subsection{Experimental Scheme Design}

Six high permeability experimental models and six low permeability models were respectively used to water flooding experiments at injection rates of $1 \mathrm{ml} / \mathrm{min}, 2 \mathrm{ml} / \mathrm{min}, 3 \mathrm{ml} / \mathrm{min}$,
$4 \mathrm{ml} / \mathrm{min}, 6 \mathrm{ml} / \mathrm{min}$ and $8 \mathrm{ml} / \mathrm{min}$.

The volumes of oil and water produced at the outlet of the experimental model at different injection pore volume multiples were recorded.

The set values of pore volume multiples were $0.25 \mathrm{PV}, 0.5$ PV, 0.75 PV, 1 PV, 1.25 PV, 1.5 PV, 2.5 PV, 3 PV and 4 PV, respectively, with a total of 10 recording points. The experimental process is shown in Fig. (1) below.

\section{ANALYSIS OF EXPERIMENTAL RESULTS}

\subsection{Water Content Characteristics}

\subsubsection{Relationship between Water Content and Pore Volume Multiplier}

According to the analysis of the experimental results, the variation of water content with the injection pore volume multiple was basically the same (Figs. 2, 3). Before the injection pore volume multiple was 1 time, the water content increases the most and tends to be gentle in the later period, which was consistent with the existing water flooding experiment. However, the changes of high permeability and low permeability samples were slightly different. Before the injection, pore volume multiple reaches 2 times, the water content of the four samples with permeability below $4 \mathrm{ml} / \mathrm{min}$ increases slowly in the early stage and rapidly in the later stage, and the curve shape was S-shaped. However, the two experimental models with injection rates of $6 \mathrm{ml} / \mathrm{min}$ and $8 \mathrm{ml} / \mathrm{min}$ show convex curves, that is, the water content increases rapidly in the early stage and slowly in the later stage. Relatively speaking, the water content rise rule of 6 experimental models of low permeability was consistent.

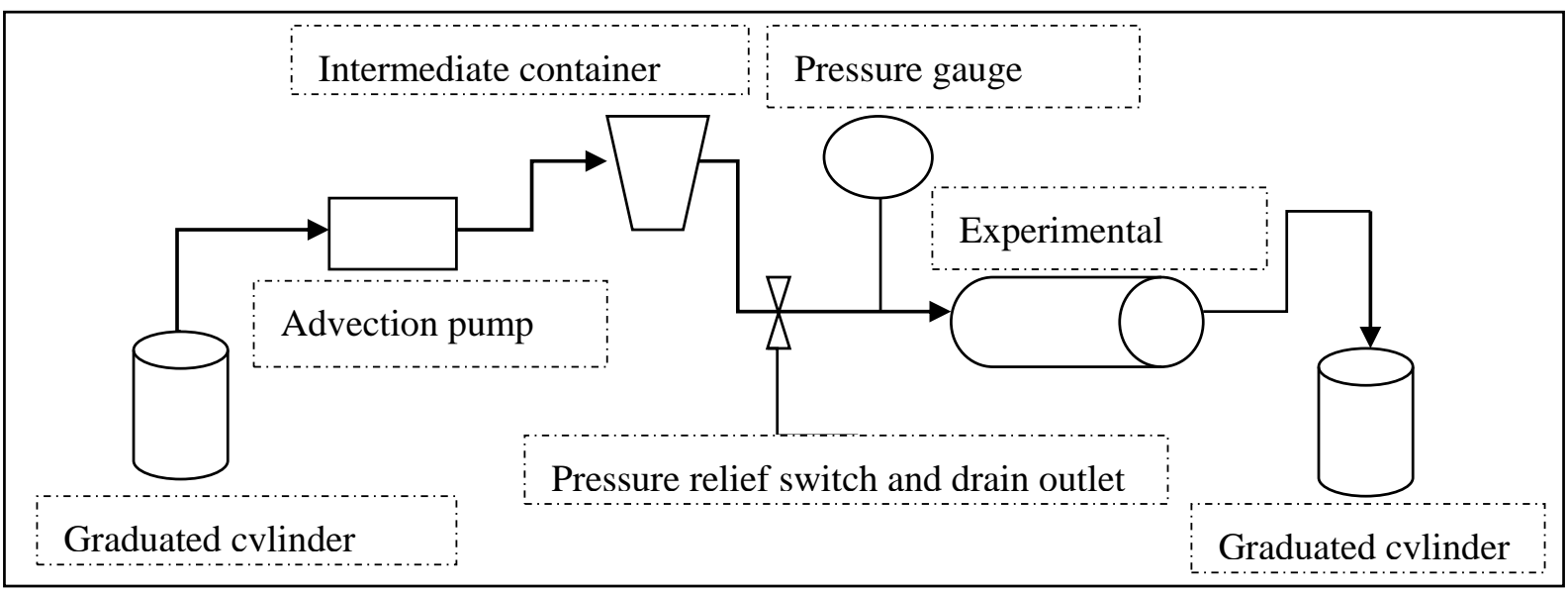

Fig. (1). Experimental flow chart. 


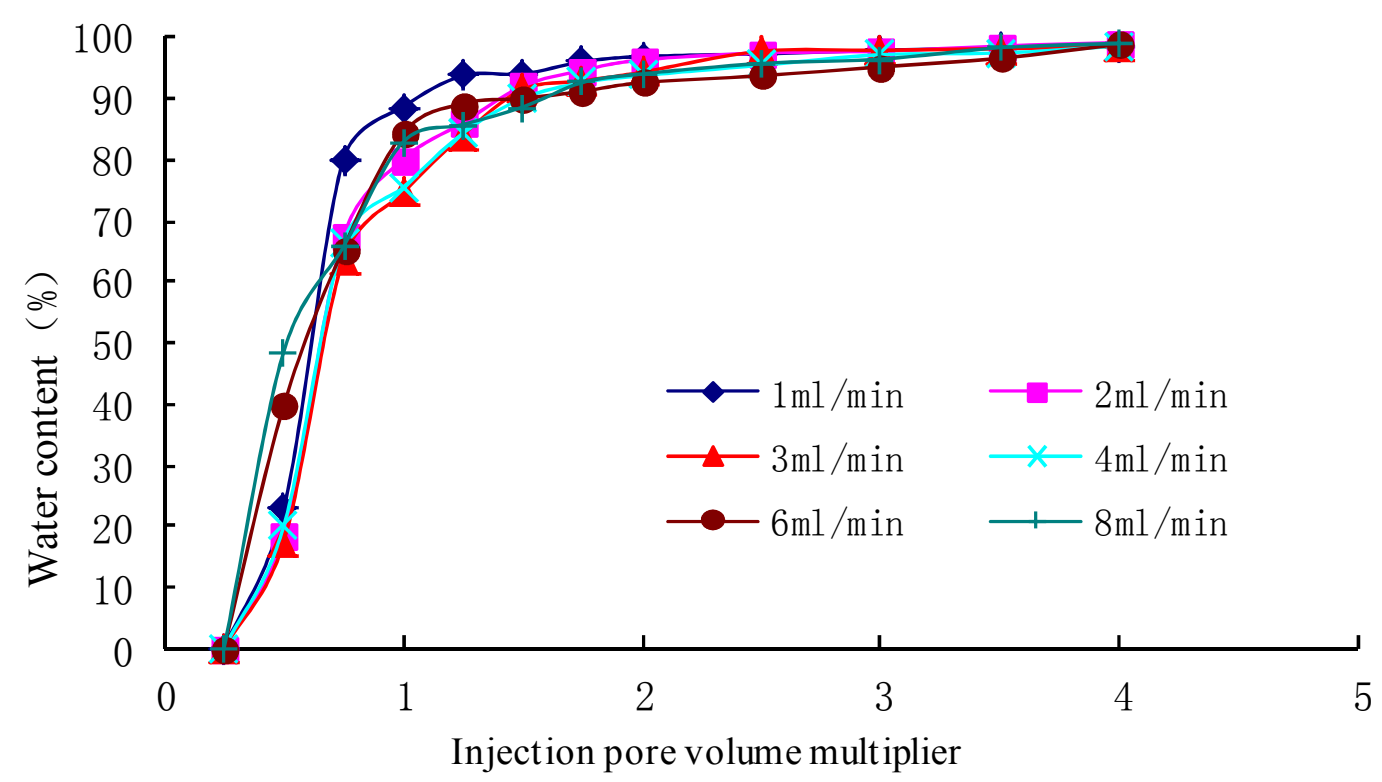

Fig. (2). Relationship between water content and injection.

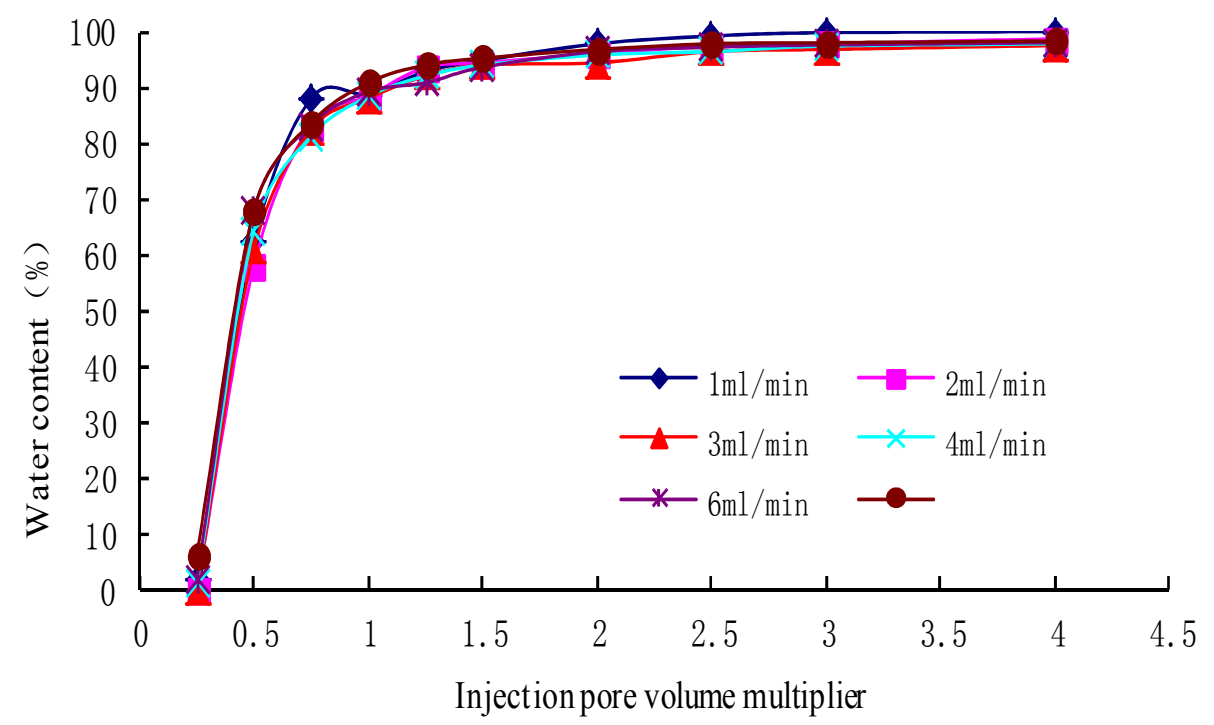

Fig. (3). Relationship between water content and injection pore volume multiplier in high permeability mode pore volume multiplier in low permeability model.

\subsubsection{Relationship Between Water Content and Injection Rate}

Seen from the relationship between water content and injection rate (Figs. 4, 5), the high permeability experimental model shows that when the injection pore volume multiple was $0.5-1.5$, the water content changes greatly, and the curve shows high at both ends and low in the middle. The water content of the injection rate of $3 \mathrm{ml} / \mathrm{min}$ was the lowest, and the water content corresponding to other injection rates was higher, and the water content increases gradually toward both ends. The low permeability experimental models with multiple pore volume multiplier $0.25-1$ times had the above characteristics. When the water content was near or above $90 \%$, the water content had little difference with the injection rate. Therefore, it was the key to improved oil displacement efficiency to adopt reasonable injection rate at early stage and control the rising rate of water content. 


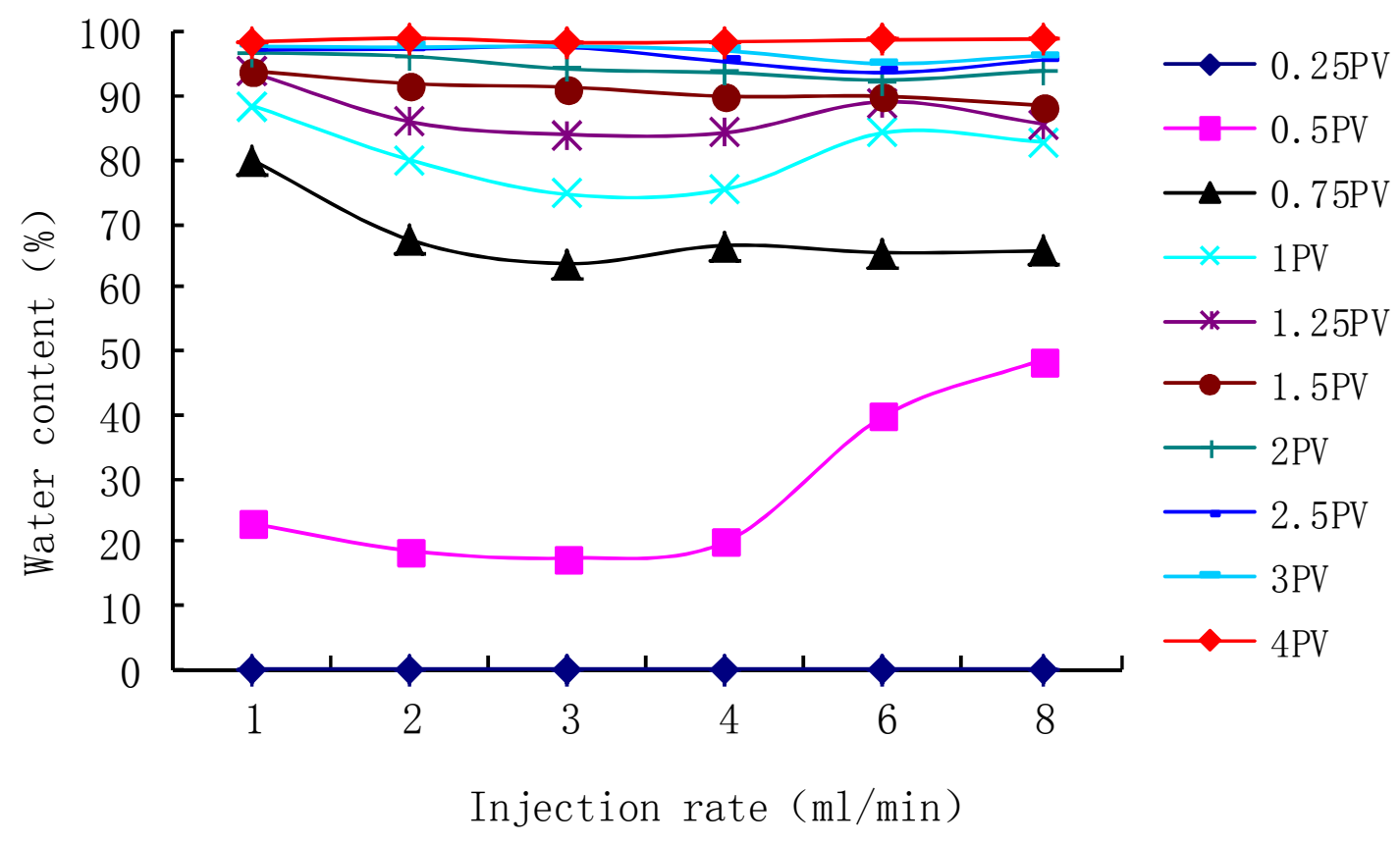

Fig. (4). Relationship between water content.

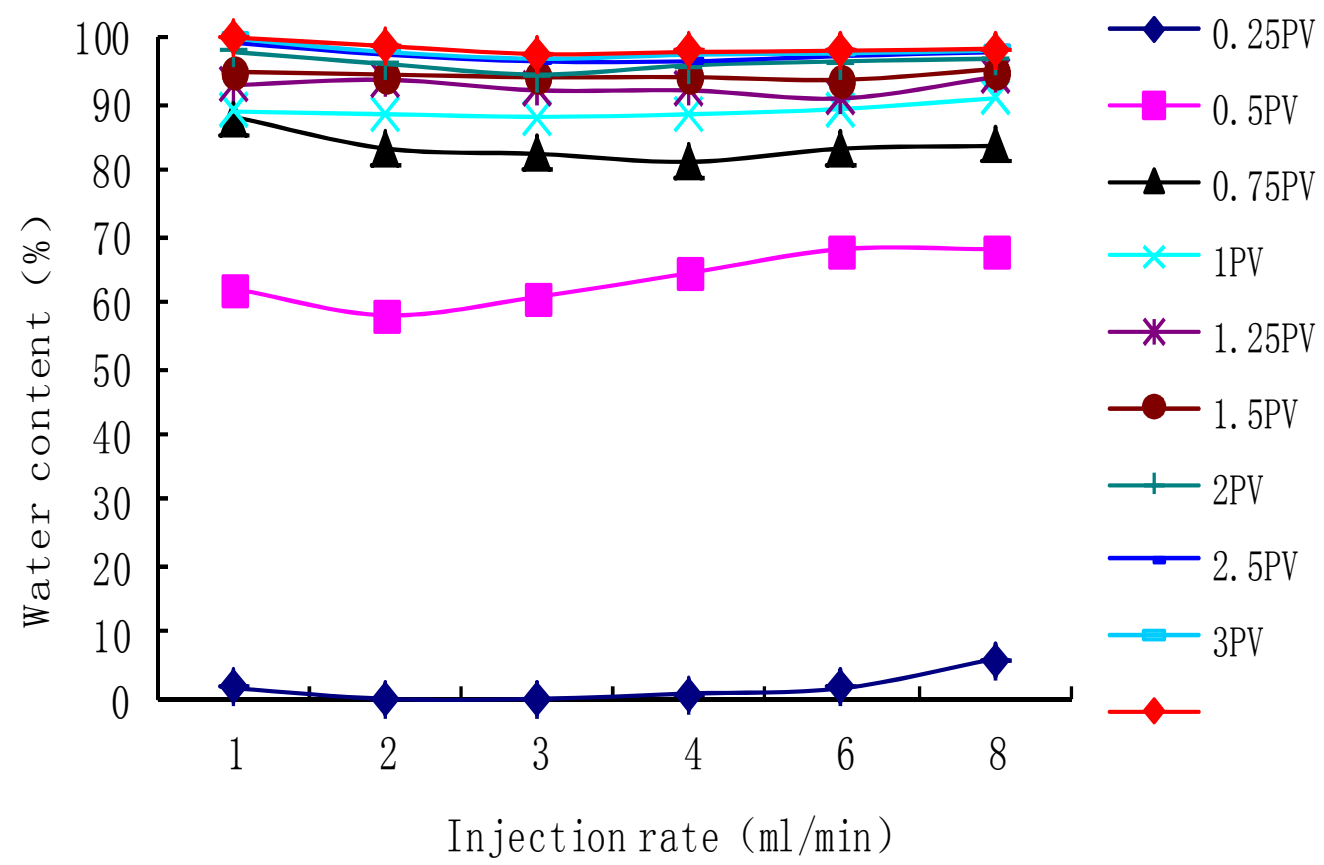

Fig. (5). Relationship between water content and injection rate in high permeability model injection in low permeability model.

\subsection{Water Displacement Efficiency}

\subsubsection{Relationship between Oil Displacement Efficiency and Injection Pore Volume Multiplier}

From the relationship between oil displacement efficiency and injection pore volume multiple (Figs. 6 and 7), it can be seen that the oil displacement efficiency of all 14 models increases with the increase of injection pore volume multiple.
And before injecting 1 time the pore volume multiple, the oil displacement efficiency had the greatest increase, the effect was the most obvious, and the later oil displacement efficiency had a small increase. These experimental results and laws were completely consistent with the previous research results, reflecting a basic law of water flooding efficiency changes. However, under different injection rates, the oil displacement efficiency was different from that of the injected pore volume. 


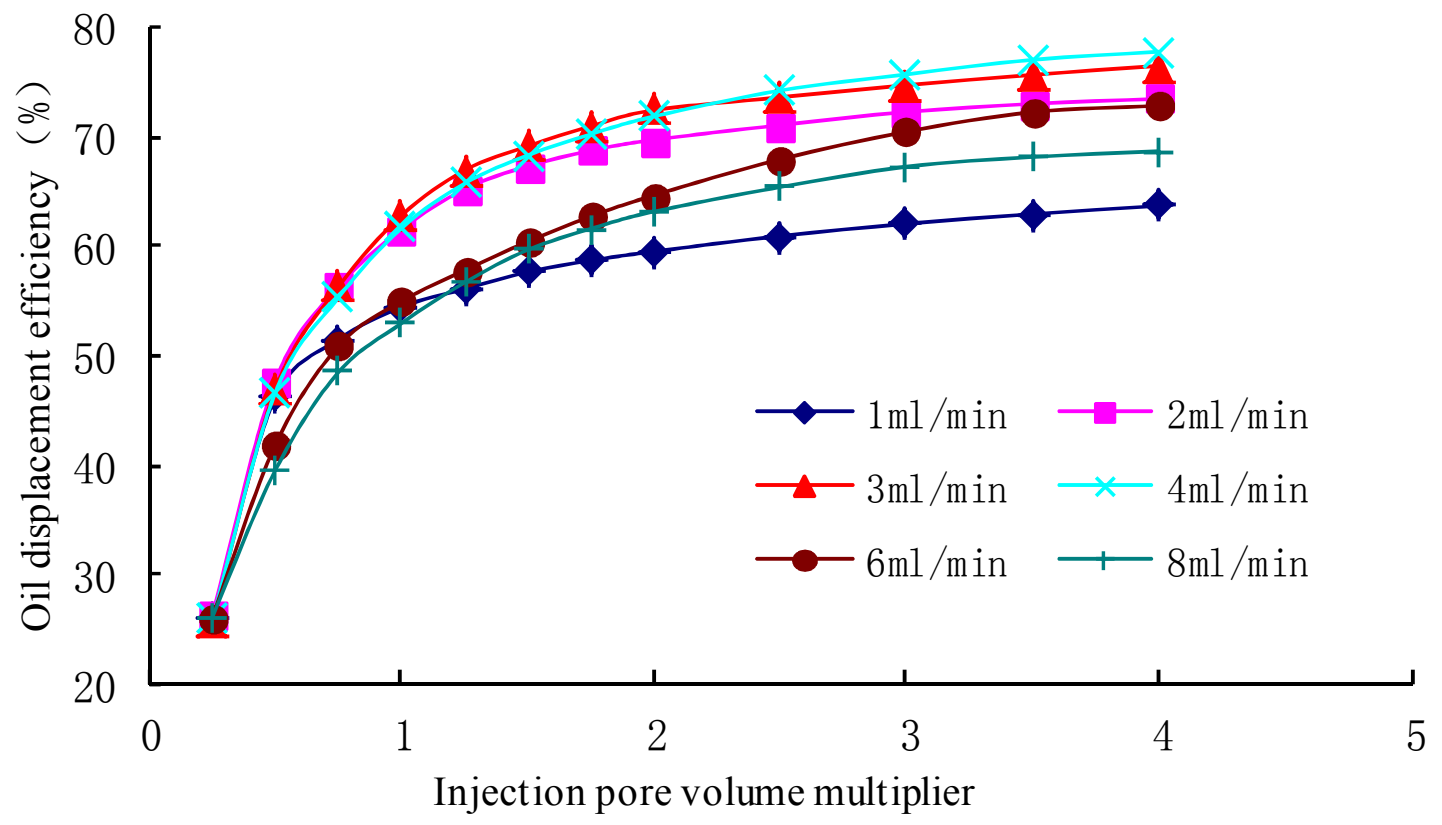

Fig. (6). Relationship between oil displacement efficiency.

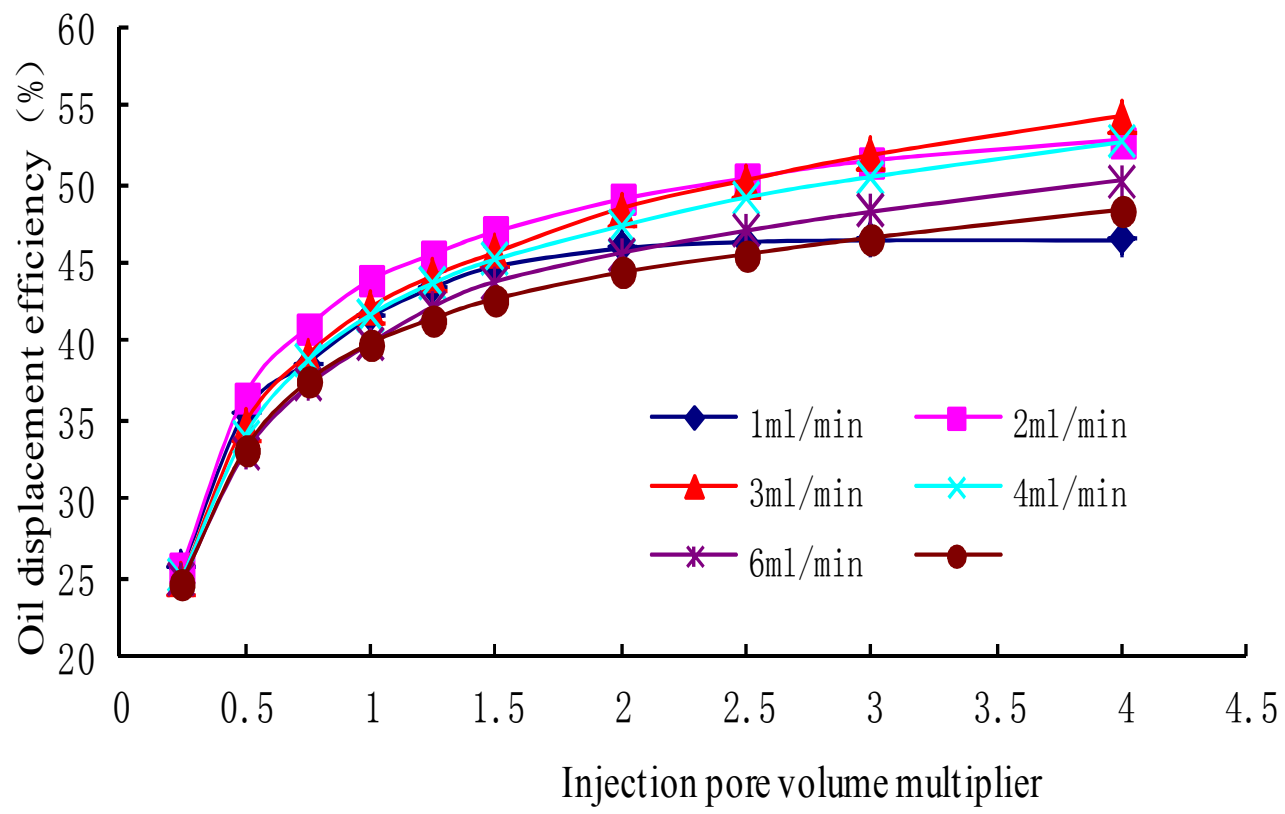

Fig. (7). Relationship between oil displacement efficiency and injection pore volume multiplier in high permeability injection pore volume multiplier in low permeability model.

\subsubsection{Relationship between Oil Displacement Efficiency and Injection Rate}

Figs. (8 and 9) show the relationship between oil displacement efficiency and injection rate of the high permeability and low permeability models, respectively. It can be seen from the diagram that when the amont of the injection was the same injection pore volume multiple, the oil displacement efficiency of each model was not the same, and changes with the change of injection pore volume multiple. At low injection rate of $1 \mathrm{ml} / \mathrm{min}$, the difference of oil displacement efficiency between the six high permeability experimental models was very small, but when the injection pore volume multiple was more than 0.5 times, the corresponding oil displacement efficiency of each model was obviously different, and the experimental results of the six low permeability models were also consistent. This indicates that the injection rate had a great influence on the oil displacement efficiency. 


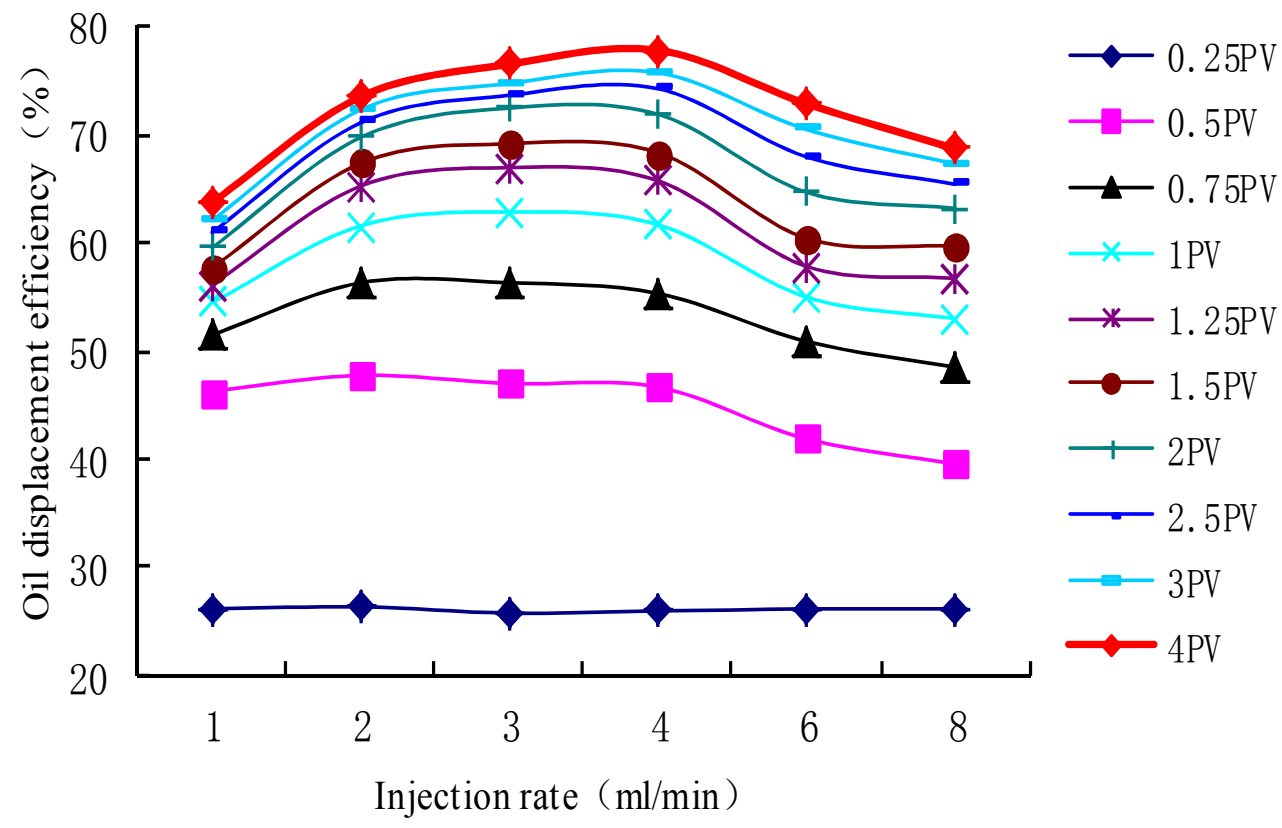

Fig. (8). Relationship between oil displacement efficiency.

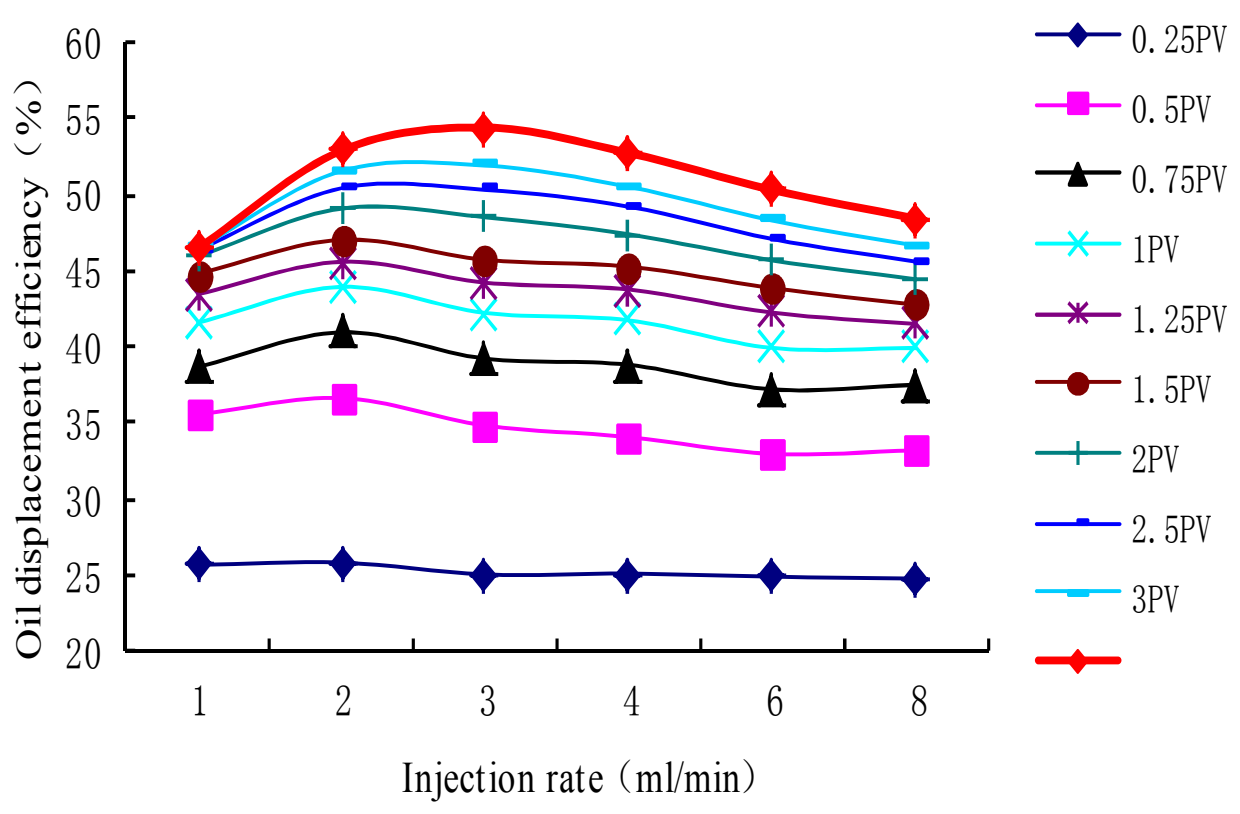

Fig. (9). Relationship between oil displacement efficiency and injection rate in high permeability mode and injection rate in low permeability mode.

When the final injection pore volume multiple reaches 4 times, the ultimate oil displacement efficiency of all experimental models was different. The lowest oil displacement efficiency of the six high permeability models was $63.73 \%$, and the corresponding injection rate was $1 \mathrm{ml} / \mathrm{min}$. The highest oil displacement efficiency was $77.85 \%$, and the corresponding injection rate was $4 \mathrm{ml} / \mathrm{min}$, with an average oil displacement efficiency of $72.22 \%$. The lowest oil displacement efficiency of the six low permeability models was
$46.46 \%$, the corresponding injection rate was $1 \mathrm{ml} / \mathrm{min}$, the highest oil displacement efficiency was $54.40 \%$, the corresponding injection rate was $3 \mathrm{ml} / \mathrm{min}$, and the average oil displacement efficiency was $50.87 \%$. From the diagram, it can be seen that the relationship between the ultimate oil displacement efficiency and injection rate was a parabolic feature, that is, there was maximum or maximum oil displacement efficiency, and the injection rate corresponding to the optimal oil displacement efficiency was the best injection 
rate. From the two kinds of models of high permeability and low permeability, the injection rate corresponding to the highest oil displacement efficiency was also different, showing that lower the permeability, the lower will be the corresponding optimal injection rate.

Under different pore volume multiples, the highest oil displacement efficiency corresponds to different injection rate. According to the high permeability model, when the injection rate was 0.25 times, 0.5 times and 0.75 times of pore volume, the injection rate with the highest oil displacement efficiency was $2 \mathrm{ml} / \mathrm{min}$. When the injection rate was $1,1.25$ times, 1.5 times and 2 times of pore volume, the injection rate with the highest oil displacement efficiency was $3 \mathrm{ml} / \mathrm{min}$, and when the injection rate reaches 2.5 times, 3 times and 4 times of pore volume, the injection rate with the highest oil displacement efficiency was $4 \mathrm{ml} / \mathrm{min}$. Similarly, the low permeability model shows that when the injection volume was 0.25-2.5 times of pore volume, the injection rate with the highest oil displacement efficiency was $2 \mathrm{ml} / \mathrm{min}$, and when the injection volume was 3 times and 4 times of pore volume, the injection rate with the highest oil displacement efficiency was $3 \mathrm{ml} / \mathrm{min}$. This phenomenon shows that with the increase of injection multiples, increasing injection rate in a certain range can increase oil displacement efficiency. At the same time, it was proved that the development effect of water flooding reservoir can be improved by liquid extraction and strong injection and strong production in the late development stage.

\section{DISCUSSION}

Through this experiment and analysis of results, further discussion and analysis were needed in the following two aspects:

(1) According to the experimental results and analysis, the maximum oil displacement efficiency of the same type of experimental model was different with different injection rates at different stages, which shows that the optimal injection rate was not unique, but varies, that is, the optimal injection rate was not the same at different injection stages. Under the actual conditions of reservoir water flooding development, reservoir heterogeneity, development methods and other conditions had more direct and prominent impact on the development effect. Therefore, it was not easy to determine the optimal injection rate of water flooding reservoirs, but through comprehensive consideration and detailed demonstration, a reasonable range of injection rate can be determined.

(2) The variation of oil displacement efficiency and water content was not the same at different injection rates, which indicates that the water content rising law of the same model was not the same at different injection rates, and also shows the variation law of oil-water relative permeability was different. Therefore, it was necessary to further study and discuss the applicability and uniqueness of oil-water two-phase relative permeability.

\section{CONCLUSION}

(1) The oil displacement efficiency was different with different water injection rate in the same permeability experimental model.
(2) The ultimate displacement efficiency and water injection rate had a certain relationship, there was a reasonable water injection rate, which can achieve the highest displacement efficiency. The injection rate to obtain the highest oil displacement efficiency was also related to the permeability of the sample. The lower the permeability, the lower will be the reasonable injection rate .

(3) At different injection stages, the injection rate corresponding to the highest oil displacement efficiency was different, and the injection rate was smaller in the early stage, and increases gradually in the later stage, and the characteristics of high permeability samples were more obvious.

(4) At a reasonable range of water injection rate, the injection rate increases gradually, and the best displacement effect can be obtained.

\section{CONSENT FOR PUBLICATION}

Not applicable.

\section{AVAILABILITY OF DATA AND MATERIALS}

Not applicable.

\section{FUNDING}

National Natural Science Foundation of China "Study on unstable water injection mechanism and parameter optimization design of heterogeneous reservoirs" (E0403-50804041).

\section{CONFLICT OF INTEREST}

The authors declare no conflict of interest, financial or otherwise.

\section{ACKNOWLEDGEMENTS}

Declared none.

\section{REFERENCES}

[1] D. Han, S. Po, and Y. Zhang, "Development model of multi-layer sandstone reservoirs [M]. Beijing", Petroleum Industry Press, vol. 24, no. 2, pp. 76-80, 2003

[2] L. Zhu, and J.X. Du Qinglong, "Characteristics and Countermeasures of the three major contradictions in the extraordinarily high water content stage of continental multi-layered sandstone reservoirs", $J$. Petrol., vol. 36, no. 02, pp. 210-216, 2015.

[3] T. Min, "Evaluation and analysis of water flooding effect in L reservoir of Laojunmiao Oilfield", J. Petrol., no. 01, pp. 46-53, 1989.

[4] JC Noirot, PJ van den Hoek, and D Zwarts, "Water Injection and Water Flooding Under Fracturing Conditions [C]", SPE-81462-MS., 2003.

[http://dx.doi.org/10.2118/81462-MS]

[5] Y. Bai, J. Li, and J. Zhou, "Effects of Physical Parameter Range on Dimensionless Variable Sensitivity in Water Flooding Reservoirs", Lixue Xuebao, vol. 22, no. 5, pp. 385-391, 2006

[http://dx.doi.org/10.1007/s10409-006-0001-1]

[6] Y. Hu, Y. Wang, and S. Yang, "Adjustment of technical guidelines for late development of Water-flooded oilfields with high water content", J. Petrol., vol. 25, no. 5, pp. 65-69, 2004.

[7] G. Yan, S. Gao, and Y. Peng, "Analysis of water flooding mechanism and recovery percent of reserves in Mobei oilfield, Xinjiang", Daqing Petroleum Geology and Development, vol. 32, no. 03, pp. 74-78, 2013.

[8] K. Wu, X. Li, and M. Ruan, "Dynamic tracking model for the reservoir water flooding of a separated layer water injection based on a well temperature log", J. Pet. Explor. Prod. Technol., vol. 5, no. 1, pp. 
35-43, 2015.

[http://dx.doi.org/10.1007/s13202-014-0105-2]

[9] J. Hou, Y. Zhang, and N. Lu, "A new method for evaluating the injection effect of chemical flooding", Petrol. Sci., vol. 13, no. 3, pp. 496-506, 2016.

[http://dx.doi.org/10.1007/s12182-016-0091-8]

[10] Quanhua Ma, Sun Wei, Shiping Wu, and He Juan, "Countermeasure analysis of improving water drive efficiency in layered sandstone reservoirs", Journal of Northwest University (Natural Science Edition), vol. 1, no. 5, pp. 413-416, 1999.

[11] Zhang Jiang, Xinfang Cheng, and Zhou Qing, "Experimental study on water drive in off-surface reservoirs of La, SA and Xing oil fields", Daqing Petroleum Geology and Development, vol. 1, no. 5, pp. 29-31+55, 1998

[12] Paulo Roberto Ballin, Shahryar Shirzadi, and Eric Ziegel, "Waterflood Management Based on Well Allocation Factors for Improved Sweep Efficiency: Model Based or Data Based [C]", SPE-153912-MS., 2012.

[13] H. Yan, Y. Lu, and A. Xu, "Effect of pore structure on water drive efficiency in Maling low permeability reservoir", J. Petrol., no. 02, pp. 45-54, 1986.

[14] H. Zhong, and H. Yin, "Reservoir Simulation for Improving Water Flooding Performance in Low-Permeability Reservoirs", Chem. Technol. Fuels Oils, vol. 49, no. 3, pp. 245-250, 2013. [http://dx.doi.org/10.1007/s10553-013-0437-5]

[15] Xiwu Zong, Zhiyun Hu, and Hongen Zhang, "Laboratory experimental study on factors affecting water drive in oil reservoirs [J]", Petroleum Drilling \& Production Technology, vol. 1, no. 01, pp. 81-86+88, 1987.

[16] JG Richardson, and FM Perkins Jr, "A Laboratory Investigation of the Effect of Rate on Recovery of Oil by Water Flooding [C]", SPE-693-
G., 1957.

[17] Mingjun Li, Yongxin Ma, and Zhixing Yang, "Experimental study on the influence of longitudinal permeability grade difference on water flooding characteristics [J]", Drilling and Production Technology, vol. 37, no. 05, pp. 47-49+9, 2014.

[18] Yuliang Su, and Li Tao, "Influence of plane heterogeneity on water flooding regularity of ultra-low permeability reservoirs [J]", Petroleum Geology and Recovery Efficiency, vol. 16, no. 01, pp. 69-71 + 115-116, 2009

[19] H. Wen, N. Sun, and Y. Liu, "Index system evaluating water flooding development effect of oilfield at ultra-high water cut stage", J. Pet. Explor. Prod. Technol., vol. 7, no. 1, pp. 111-123, 2017. [http://dx.doi.org/10.1007/s13202-016-0249-3]

[20] Cui Yue, and Jingping Shi, "Index system evaluating water flooding development effect of oilfield at ultra-high water cut stage [J]", Journal of Petroleum Exploration and Production Technology, vol. 7, no. $1,-1232017.111$

[21] Dickey Parke A, Buckwalter John F, and Andersen Kurt H, "Increasing and Maintaining Injection Rates Of Water-Input Wells [C]", API-46-228., 1946.

[22] Singhal Ashok K, "Improving Water Flood Performance by Varying Injection-Production Rates[C]", PETSOC-2009-126., 2009.

[23] Feilong Liu, and David Shipley Charles F Guthrie, "Optimizing Water Injection Rates for a Water-flooding Field[C]", SPE-157996-MS., 2012.

[24] K. Yu, K. Li, and Q. Li, "A method to calculate reasonable water injection rate for M oilfield", J. Pet. Explor. Prod. Technol., vol. 7, no. 4, pp. 1003-1010, 2017.

[http://dx.doi.org/10.1007/s13202-017-0356-9]

C) 2019 Yang et al.

This is an open access article distributed under the terms of the Creative Commons Attribution 4.0 International Public License (CC-BY 4.0), a copy of which is available at: https://creativecommons.org/licenses/by/4.0/legalcode. This license permits unrestricted use, distribution, and reproduction in any medium, provided the original author and source are credited. 